\title{
LVIII. On a method of driving tuning-forks electrically
}

\section{W. G. Gregory M.A.}

To cite this article: W. G. Gregory M.A. (1889) LVIII. On a method of driving tuning-forks electrically, Philosophical Magazine Series 5, 28:175, 490-492, DOI: $10.1080 / 14786448908619895$

To link to this article: http://dx.doi.org/10.1080/14786448908619895

曲 Published online: 08 May 2009.

Submit your article to this journal $[\pi$

Џ Article views: 2

Q View related articles $\asymp$ 
single observations the curve of error would perhaps be something like fig. 14.

Fig. 14.

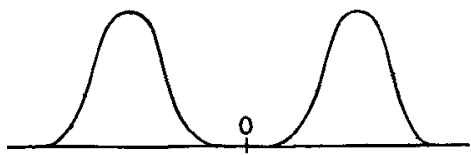

14. As a final example, suppose we are trying to place a small round body in a given position in a plane. Here the law of error will depend on our manner of testing the adjustment : whether we merely look up and down and from side to side to get two (very nearly independent) judgments of the corresponding coordinates, or whether we examine the object from every point of view to make sure that no error can be detected. The case may be illustrated mechanically by supposing two pendulums supported one on gimbals, the other after the manner of Foucault's pendulum; appropriate laws of friction being assumed. The law of error will further depend on whether we follow the method of $\S 12$ or of $\S 13$.

If we were trying to drive a billiard ball from one given position so as to make it come to rest in another given position (without rebounds), the errors of direction and of distance would, if small, be very nearly independent; the latter coordinate being probably subject to much greater variation.

We are led, then, to the following conclusions:-The law of error in a set of observations depends on the nature of each special case; and what may be called the probable law of error is determined by our knowledge of the conditions. The combination of three or more sources of error of comparable importance gives in general a law of frequency not seriously differing from that of Laplace; so that the method of least squares will be practically the most advantageous, except where a single source of error with a very different law is predominant above all the rest.

LVIII. On a Method of Driving Tuning-Forks Electrically By W. G. Gregory, M.A., Demonstrator in Physics at the Royal Indian Engineering College, Coopers Hill*

T the ordinary method of driving tuning-forks by elec1 tricity, the battery circuit is com pleted just before the end of the stroke and broken again soon after the commencement of the return motion. Thus the fork receives its impulse at a

* Communicated by the Physical Society: read November 1, 1888. 
most unfavourable moment, i. e. when it is stationary. The impulse can be considerably delayed by including in the battery circuit a solenoid into which a solid iron core is inserted more or less till the best result is obtained. This adjustment, however, varies with the amplitnde of vibration and the alterations of the contact. The whole matter was discussed in a paper read before the Physical Society on June 26th, 1886, by Prof. S. P. Thompson*, who then suggested the employment of two similar forks which drove one another and settled down to a difference of phase of a quarter of a period. Each fork, therefore, received an impulse when moving at its greatest velocity in the middle of its stroke.

The method I now suggest accomplishes the same thing without the employment of a second fork, and moreover gives two impulses in each complete period instead of one.

The arrangement is shown in fig. 1.

Fig. 1.

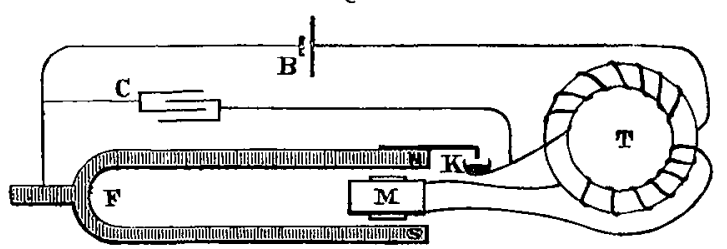

$\mathrm{F}$ is a tuning-fork mounted in the usual way, and provided with a driving electromagnet $M$, and contact-maker $K$. But instead of taking the main battery-current directly through the electromagnet $M$, it is sent through the primary coil of a kind of transformer $\mathrm{T}$, the secondary circuit of which is connected to the electromagnet. Hence, at both make and break of the main circuit, momentary induced currents pass through the driving magnet alternately in opposite directions. By polarizing the fork so as to make it a horseshoe-magnet, the impulses are also made to act alternately as attractions and repulsions, and the fork receives two impulses for each complete vibration. By properly adjusting the contact when the fork is at rest, so as just to complete the circuit, the impulses will be given very approximately at the middle of the stroke, and are independent of the amplitude of vibration. The fork I tried made about 86 vibrations per second, and had prongs 20 cms. long and $1.8 \mathrm{~cm}$. apart. The electromagnet $M$ was formed by winding about 50 turns of no. 22 silk-covered copper wire round a core formed of a bundle of varnished iron wire. It was mounted on a wooden support capable of sliding between and parallel to the prongs. The transformer $\mathrm{T}$ consists of a core * Proc. Phys. Soc. viii. pt. ii. ; Phil. Mag. [5] xxii. p. 216. 
of cotton-covered iron bonnet-wire wound in the form of an anchor-ring having a mean diameter of $6 \mathrm{cms}$. and thickness $1 \mathrm{~cm}$. Round this is wound the secondary coil of about 160 turns of no. 22 silk-covered copper wire, forming a single layer completely round, and outside this the primary of about 190 turns of similar wire. A condenser $C$ of 4 microfarads capacity was connected across the mercury-break $\mathrm{K}$ to diminish the sparking. One small accumulator B sufficed to work the fork vigorously, the mean current consumed being about 2 amperes. By increasing the number of turns of wire, much less current would be required, but there would be a limit, since the lag must not be so great as to interfere with the proper timing of the impulses.

An alternative method, using far less current but requiring two contacts, is shown in fig. 2 .

Fig. 2.

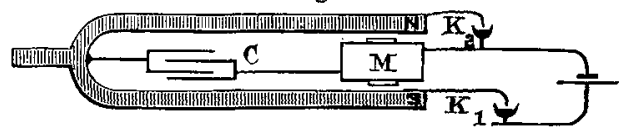

The contact $K_{1}$ charges the condenser $C$ and $K_{2}$ discharges it. The currents of charge and discharge are both taken through the electromagnet $M$, and the action is the same as above, the fork being, of cuurse, polarized. It would be necessary to wind the magnet $M$ with many turns of wire, to use a battery of high E.M.F. and a large condenser. The latter, however, could probably be replaced by a polarizable battery of platinum or lead wires in dilute sulphuric acid. Except for economy of working, it is not so good a method as the first, as the adjustments of the contacts $K_{1}$ and $K_{2}$ must be very exact.

As regards magnetizing the fork, there can be no real objection to that, for in the usual method of driving it soon acquires a polarity. In fact the fork I first tried worked at once without any further magnetization.

LIX. Proceedings of Learned Societies.

GEOLOGICAL SOCIETY.

[Continued from p. 144.]

November 6, 1889.-W. T. Blanford, LL.D., F.R.S., President, in the Chair.

THE following communications were read :-

1. "Contributions to our Knowledge of the Dinoeaurs of the Wealden and the Sauropterggians of the Purbeek and Oxford Clay." By R. Lydekker, Esq., B.A., F.G.S. 